Departamento de Química Orgânica e Biológica

Diretor: Prof. Dr. Fonseca Ribeiro

\title{
MICRORREAÇÃO QUALITATIVA PARA PESQUISAS DO ION BÓRICO, NO LEITE
}

POR

\section{Virgilio Bonoldi}

Assistente

E' prática corrente, nas pesquisas do ion bórico, utilizado muitas vezes como conservador do leite, o emprego do método da Curcuma ou o da coloração da chama; o primeiro sendo mais sensivel que o segundo é, não obstante, menos específico e não é raro, por isso, que nas análises de rotina, fique o analista em dúvida quanto ao verdadeiro significado das reações. Justificavel portanto o estudo de um novo test que obviasse os inconvenientes daqueles métodos, e nessa ordem de idéia ocorreu-nos utilizar a reação descrita por ZoRKIN (*) na análise dos minerais.

\section{PARTE EXPERIMENTAL}

$O$ método se fundamenta na modificação de cor que confere o ion bórico a uma solução de carmim em ácido sulfúrico concentrado provavelmente pela formação de um ester complexo do ácido bórico.

Reativo - Solução a $0,05 \%$ de carmim em ácido sulfúrico $(\mathrm{D}=1,825)$. A solubilização é completa embora lenta (cerca de 24 horas) e o reativo se conserva indefinidamente, quando em vidro fechado para evitar a diluição do ácido.

Método de análise: transfere-se $1 \mathrm{~cm} .^{3}$ do reativo para cada um de dois pequenos tubos de ensaio (tamanho $10 \times 10$ ) e a um deles se junta uma pequena gota do leite a examinar com um bastão de vidro ou pipeta de pequeno orifício; agita-se ligeiramente e após cinco minutos de repouso, à temperatura ambiente, compara-se a cor deste tubo com a do que recebeu apenas o reativo (testemunho). A reação é positiva quando aparece coloração violeta, sendo vermelha a cor do reagente. E’ facilmente compreensivel que com alguma prática não será necessário o uso do tubo testemunho ou que este seja apenas utilizado em casos de dúvida.

\section{APLICABILIDADE DO MÉTODO}

A aplicabilidade do método dependeria, evidentemente, de sua sensibilidade e da ausência de alteração de cor do reativo pelo contacto com um leite isento do ion bórico (especificidade). Cuidamos de 
início desta segunda parte reconhecendo que o leite isento de ácido bórico não altera a cor do reativo quer se trate de leite cru, fervido, pasteurizado ou refrigerado, inclusive depois de envelhecido. Nesta prova preliminar utilizamos por diversas vezes leites de pequena e de grande mistura, sempre com os mesmos resultados.

Para a determinação da sensibilidade do método, partimos de u'a amostra de leite experimentalmente adicionado de borax na proporção de $1 \%$ e daí realizámos diluições progressivas até 1/512 em que uma gota $\left(1 / 20 \mathrm{~cm}^{3}\right.$.) equivalia a $1,0 \gamma$ de borax. Neste último tubo da série a reação é ainda positiva, embora não muito evidente, (aumento de intensidade na cor do reativo). Importa notar, todavia, que esta diluição equivale ao emprego de borax na quantidade de $0,0002 \%$ gr. o que está muito aquem de qualquer efeito conservador desse sal para o leite e portanto foge à conveniência do fim a que se destina, na adulteração do produto.

Com as quantidades de hábito utilizadas, nas tentativas de conservação do leite pelo borax $(1 \%)$, a reação é francamente positiva não interferindo, como pudemos determinar, os processos de manipulação por que passa o leite nem o seu envelhecimento.

Estes resultados autorizam a aplicação da reação de ZoRKIN à pesquisa do ion bórico utilizado fraudulentamente na conservação do leite. O test é simples, rápido, sensivel e específico. (*)

\section{RESUMO}

$\mathrm{O}$ autor aplica o reativo carmim-sulfúrico $(0,05 \%$ de carmim em ácido sulfúrico $\mathrm{D}=1,825)$ para a identificação do ion bórico no leite. A técnica descrita é extraordinariamente simples sendo a reação específica e de grande sensibilidade.

\section{Abstract}

The author employs the reactive sulfuric-carmine $(0,05 \%$ of carmine and sulfuric acid $D=1,825)$ for the identification of the boric ion in the milk. The described method is extraordinarily simple, the reaction being specific and of great sensibility.

\footnotetext{
O papel perturbador dos nitritos, nitratos ou outros oxidantes, possivelmente presentes no leite, será afastado por aquecimento dos tubos. (inclusive o testemunho), em banho-maria - 15 minutos - caso em que, se presente algum desses oxidantes, o reagente readquirirá sua cor primitiva. Esse aquecimento é necessario sempre que se suspeitar da presença deles no leite.
} 